\title{
Development of Vitamin D Determination in Infant Formula by Column-Switching HPLC with UV Detector
}

\author{
Jinhyouk Ko, Byung-Man Kwak, Jang-Hyuk Ahn*, Sung-Lye Shim', Kyong-Su Kim¹, \\ Taehyung Yoon ${ }^{2}$, Dong-gil Leem², and Jayoung Jeong ${ }^{2}$ \\ Food Safety Center, Research and Development Institute, Namyang Dariy Co. Ltd., Gongju 314-914, Korea \\ ${ }^{1}$ Department of Food and Nutrition, Chosun University, Kwangju 501-759, Korea \\ ${ }^{2}$ Nutrition and Functional Food Research Team, Korea Food and Drug Administration, Seoul 122-704, Korea
}

\begin{abstract}
This study was carried out to develop an analytical method for the determination of vitamin D in infant formula Vitamin D was determined by column-switching high-performance liquid chromatography (HPLC) equipped with a reversed phase column and UV detector after saponification and extraction of the formula with an organic solvent. A preseparation column $\left(\mathrm{C}_{8}\right)$, focusing column $\left(\mathrm{C}_{18}\right)$, analytical column $\left(\mathrm{C}_{18}\right)$ and UV-Vis detector $(254 \mathrm{~nm})$ were used. The limits of detection (LOD) and the limits of quantification (LOQ) for vitamin D were estimated to be $1.51 \mu \mathrm{g} / \mathrm{kg}$ and 4.95 $\mu \mathrm{g} / \mathrm{kg}$, respectively. The linearity, recovery, precision and accuracy of the analytical method for vitamin D were evaluated through the application of a SRM (Standard Reference Material) 1846 (National Institute of Standard \& Technology, USA). The linearity of this method was calculated with a value of the coefficient of determination $\left(r^{2}\right)$ $\geq 0.9999$. The recovery of vitamin D was $85.20 \pm 3.00 \%$. The intra-assay precision for vitamin $\mathrm{D}$ was between $1.68 \pm 0.03 \%$ and $5.75 \pm 0.33 \%$, and the inter-assay precision for vitamin D ranged from $1.73 \pm 0.03 \%$ to $2.96 \pm 0.09 \%$. The intra-assay accuracy for vitamin D was between $100.03 \pm 2.77 \%$ and $102.01 \pm 0.59 \%$, and the inter-assay accuracy for vitamin D ranged from $99.00 \pm 1.53 \%$ to $102.01 \pm 3.04 \%$. The proposed method is optimal for the separation and quantification of vitamin D from infant formula.
\end{abstract}

Key words: vitamin D, column-switching high-performance liquid chromatography, UV detection, infant formula

\section{Introduction}

Infant formula consists of various ingredients, including inorganic matter and vitamins to supply the nutritional requirements of infants and children (Codex, 2007). Infant formula is the only processed foodstuff that entirely satisfies the nutritional requirements of infants during the first months of life until the introduction of appropriate complementary feeding (The commission of the European communities, 2006). Among the nutritional ingredients in infant formula, the vitamin D is very low levels of fat-soluble vitamin (Heudi et al., 2004). Vitmain $\mathrm{D}$ is one of the most important essential bioregulators of the $\mathrm{Ca}^{2+}$ and phosphate metabolism in higher animals (Friedrich, 1988). Vitamin D and its hydroxyl metabolites

*Corresponding author: Jang-Hyuk Ahn, Food Safety Center, Research and Development Institute, Namyang Dariy Co. Ltd., Gongju 314-914, Korea. Tel: 82-41-856-0381, Fax: 82-41-8577933,E-mail: ppori5470@hotmail.com play significant roles as hormonal regulators of calcium metabolism and are associated primarily with bone health (Bell et al., 1979). Vitamin D deficiency leads to rickets in children and osteomalacia in adults (Friedrich, 1988) and the quantification of vitamin D is widely used as a means of clinical testing for several pathophysiological states (e.g., parathyroid gland disorders, renal failure, vitamin-dependent rickets and sarcoidosis) (Donald and Gerhard, 1992). For this reason, the accurate determination of low levels of vitamin D in infant formula is crucial to safeguard the health of infants and children.

Traditionally, the existing procedures for vitamin D determination include colorimetric method (Gharbo and Gosser, 1974; Hassan, 1980), high-performance liquid chromatographic method with UV detection (AOAC, 2005; KFDA, 2009) and mass spectrometry (Heudi et al., 2004; Kamao et al., 2007; Soldin et al., 2009). Complex matrix sample, such as infant formula, requires a highly complicated sample preparation methods to remove interference for detection of low level vitamin D. The high- 
performance liquid chromatographic (HPLC) method by KFDA (2009) and AOAC (2005) consists of two steps to remove interference in infant formula. Vitamin D fractions are collected from interfering substances on a cleanup column, and then an analytical procedure is carried out. However, this procedure is complicated and requires a long period of time; therefore, it is not suitable for handling a lot of samples. Recently, column-switching high performance liquid chromatographic method is used to eliminate the complicated sample cleanup step in sample preparation. Column-switching method is a rapid automated online extraction procedure and is successfully used to identify a wide range of analytes in complicated samples (Brunetto et al., 2004; Christians et al., 2000; Hartmann et al., 2001; Knebel et al., 2000). This study aims to develop vitamin $\mathrm{D}$ detection method in infant formula by column-switching high performance liquid chromatography with a rapid automated online extraction procedure without complicated sample cleanup step.

\section{Materials and Methods}

\section{Reagents and materials}

The experiments were performed using infant formula SRM (Standard Reference Material) 1849 (National Institute of Standard \& Technology, USA), which contains $117.00 \pm 11.00 \mu \mathrm{g} / \mathrm{kg}$ of vitamin D. Sixteen kinds of commercial infant formula samples were collected from different markets in Daejeon, Korea. These samples were kept at room temperature. All reagents and solvents used were of HPLC or analytical reagent grade. The vitamin D standard was purchased from Sigma (USA). Water, methanol, absolute ethanol and hexane were obtained from E. Merck (Germany). Pyrogallol was supplied from Samchun Pure Chemical (Korea). Potassium hydroxide and sodium sulfate were purchased from Junsei Chemical (Japan). High-purity water was obtained through an Easy Pure system (Barnstead, USA).

\section{Standard solutions}

A stock solution $(1000 \mathrm{mg} / \mathrm{L})$ of the vitamin D standard was prepared in a $100 \mathrm{~mL}$ volumetric flask by dissolving $0.1 \mathrm{~g}$ of vitamin $\mathrm{D}$ in $100 \mathrm{~mL}$ of methanol. Working standards were prepared daily for analysis by diluting the vitamin D stock standard solution in a solution of methanol:ethanol: $\mathrm{H}_{2} \mathrm{O}(74.7: 8.3: 17, \mathrm{v} / \mathrm{v})$ to the desired range of $10-100 \mu \mathrm{g} / \mathrm{L}$.

\section{Sample preparation}

Sample preparation, except for the dissolving step in water, sample volume and final elute solution volume, was performed by the KFDA official method (KFDA, 2009). The sample preparation procedure was optimized by improving a previous extraction procedure with organic solvents. $1 \mathrm{~g}$ of infant formula ( $5 \mathrm{~g}$ liquid sample) was weighed accurately and transferred into a $250 \mathrm{~mL}$ brown round-bottom flask. After the addition of $3 \mathrm{~mL}$ of water, the flasks were shaken enough to dissolve the formula. $40 \mathrm{~mL}$ of $10 \%$ pyrogallol:ethanol $(1: 10, \mathrm{w} / \mathrm{v})$ was added, and the flasks were shaken slowly. $10 \mathrm{~mL}$ of $\mathrm{KOH}: \mathrm{H}_{2} \mathrm{O}(9: 1, \mathrm{w} / \mathrm{v})$ was added, and the samples were refluxed for $30 \mathrm{~min}$ in a steam bath at $90^{\circ} \mathrm{C}$. The samples were cooled rapidly under running $\mathrm{H}_{2} \mathrm{O}$. After the addition of $50 \mathrm{~mL}$ of hexane, the flasks were shaken vigorously three times for $10 \mathrm{~min}$ each.

The collected hexane extract liquid was transferred to brown separatory funnels with $100 \mathrm{~mL}$ of $1 \mathrm{~N} \mathrm{KOH}$. The funnels were shaken vigorously for $15 \mathrm{~s}$. They were allowed to stand until both layers were clear, and then the aqueous layer was drained. $40 \mathrm{~mL}$ of $0.5 \mathrm{~N} \mathrm{KOH}$ was added, and the mixture was shaken vigorously for $15 \mathrm{~s}$. The funnels were allowed to stand until both layers were clear, and the aqueous layer was then drained. The remaining fraction was washed with $50 \mathrm{~mL}$ portions of $\mathrm{H}_{2} \mathrm{O}$ until the last washing was neutral to phenolphthalein. The last few drops of $\mathrm{H}_{2} \mathrm{O}$ were drained, and the remaining sample was dehydrated by sodium sulfate. The hexane layer was collected in a $250 \mathrm{~mL}$ brown round-bottom flask and evaporated to dryness under a vacuum by swirling in a water bath at $\leq 40^{\circ} \mathrm{C}$. The residue was dissolved immediately in $5 \mathrm{~mL}$ of $\mathrm{MeOH}$ and filtrated by a PTFE filter. A $210 \mu \mathrm{L}$ aliquot of this solution was then ready to be injected into the column-switching HPLC system.

\section{Instruments}

The experiments were performed using a liquid chromatographic Shiseido NANO SPACE SI-2 system (Shiseido, Japan) connected to a Shiseido UV-Vis detector and with SMC-21 software for instrument control and data collection and processing. Detection was carried out at $254 \mathrm{~nm}$. Injections were made with a $100 \mu \mathrm{L}$ loop. For columnswitching purposes, a column-switching six-port valve (Shiseido, Japan) controlled by the SMC-21 software was used, along with an additional pump 3001 (Shiseido, Japan) to deliver the extraction mobile phase. 


\section{Column-switching HPLC system}

\section{Pre-separation step}

At this step, a volume of $30 \mu \mathrm{L}$ of $1 \mathrm{mg} / \mathrm{L}$ of a vitamin D standard solution was injected onto the pre-separation column using the pre-separation mobile phase. The switching valve position is load position. While the endogenous compounds were flushed to waste, the analytes were retained by the hydrophobic inner surface of the pre-separation column. The pre-separation efficiency and retention time were considered with eight different mobile phases and three types of columns for establishing the optimum condition. The reverse phase $\mathrm{C}_{8}$ (Capcellpak MF, $4.6 \times 150 \mathrm{~mm}, 5 \mu \mathrm{m}$ ), $\mathrm{C}_{18}$ (Sunfire, $4.6 \times 150 \mathrm{~mm}$, $3.5 \mu \mathrm{m})$ and $\mathrm{C}_{18}(\mathrm{ODP} 2 \mathrm{HP}-4 \mathrm{D}, 4.6 \times 150 \mathrm{~mm}, 5 \mu \mathrm{m})$ columns were tested. The mobile phase composition was tested with methanol:ethanol: $\mathrm{H}_{2} \mathrm{O}(74.7: 8.3: 17, \mathrm{v} / \mathrm{v})$, methanol: $\mathrm{H}_{2} \mathrm{O}(90: 10, \mathrm{v} / \mathrm{v})$, methanol: $\mathrm{H}_{2} \mathrm{O}(80: 20$, v/v), acetonitrile: $\mathrm{H}_{2} \mathrm{O}(90: 10, \mathrm{v} / \mathrm{v})$, acetonitrile: $\mathrm{H}_{2} \mathrm{O}(85: 15, \mathrm{v} / \mathrm{v})$, methanol: $\mathrm{H}_{2} \mathrm{O}(75: 25, \mathrm{v} / \mathrm{v})$, methanol: $\mathrm{H}_{2} \mathrm{O}(70: 30, \mathrm{v} / \mathrm{v})$ and acetonitrile: $\mathrm{H}_{2} \mathrm{O}(80: 20, \mathrm{v} / \mathrm{v})$.

\section{Focusing step}

A $1 \mathrm{mg} / \mathrm{L}$ vitamin D standard solution was injected onto a pre-separation column to determine the switching time $30 \mathrm{~s}$ before and after the vitamin $\mathrm{D}$ peak. While determining the switching time, the switching valve was in the inject position, and the pre-separation column, focusing column were connected in series. At the focusing step, the reverse phase $\mathrm{C}_{18}$ (Capcell-pak UG120V, $2.0 \times 35 \mathrm{~mm}, 5 \mu \mathrm{m}$ ) column was used in focusing column and ethanol:methanol (10:90, v/v) was used in mobile phase.

\section{Analytical step}

After switching time is setted, the switching valve was changed back to the load position to recondition the preseparation column with the pre-separation mobile phase to be ready for the next injection. In the meantime, the analytes were separated in the analytical column under isocratic mode elution and detected by the UV-Vis detector at $254 \mathrm{~nm}$. The analytical column efficiency was considered with two different mobile phases and a column for establishing the optimum condition. The reverse phase $\mathrm{C}_{18}$ (Capcell-pak UG120V, 4.6 $\times 250 \mathrm{~mm}, 5 \mu \mathrm{m}$ ) column was tested. The two different mobile phases were methylene chloride:methanol (10:90, v/v) and ethanol:methanol $(10: 90, \mathrm{v} / \mathrm{v})$.

\section{Validation}

The method validation were evaluated in terms of linearity, LOD, LOQ, accuracy, precision, recovery and interlaboratory test according to $\mathrm{ICH}$ harmonized tripartite guideline, IUPAC technical report and AOAC guideline (AOAC Committee report, 1989; ICH Expert Working Group, 2005; Michael et al., 2002). The linearity was evaluated by the coefficient of determination $\left(\mathrm{r}^{2}\right)$ and was calculated for three consecutive standard curves. The limits of detection (LOD) and quantification (LOQ) were determined by serial dilutions of vitamin $\mathrm{D}$ solutions to obtain signal/noise ratios of approximately 3:1 for LOD and approximately 10:1 for LOQ. To evaluated accuracy and precision, samples spiked with three levels concentrations of vitamin D $(10,40$ and $80 \mu \mathrm{g} / \mathrm{L})$. The accuracy was determined by comparing the theoretical concentrations of vitamin D standards and those obtained by chromatographic analysis. This was expressed as a percentage of the mean of the quantitative values of the reference samples, was calculated as (contentdetermined in spiked sample-contentdetermined in unspiked sample)/spiked content $\times 100$. The precision, which was calculated as the relative standard deviation (R.S.D., \%), was obtained at three levels: intra-(within $24 \mathrm{~h}$ ) and inter-day (for three consecutive days) precision. The recovery rates were calculated by comparing the theoretical concentrations of vitamin D in SRM 1846 and those obtained by chromatographic analysis. To evaluate inter-laboratory tests of this method, a recovery test was performed by three laboratories. Sixteen kinds of commercial infant formula were collected from different markets in Daejeon, Korea. These samples were kept at room temperature. The pre-separated samples were analyzed by HPLC with a switching valve. Every experiments for the method validation were analyzed in three replicates.

\section{Results and Discussion}

\section{Column-switching HPLC system optimization}

\section{Pre-separation step}

Eight different mobile phases and three types of columns were tested. The reverse phase $\mathrm{C}_{8}$ (Capcell-pak MF, 4.6× $150 \mathrm{~mm}, 5 \mu \mathrm{m})$ column and methanol:ethanol: $\mathrm{H}_{2} \mathrm{O}(74.7$ : $8.3: 17, \mathrm{v} / \mathrm{v}$ ) were selected as the optimum conditions for the pre-separation step. A working mobile phase of methanol:ethanol: $\mathrm{H}_{2} \mathrm{O}(74.7: 8.3: 17, \mathrm{v} / \mathrm{v})$ elevated the retention time to $12 \mathrm{~min}$, providing high-resolution separation of vitamin D from endogenous compounds. The separated 


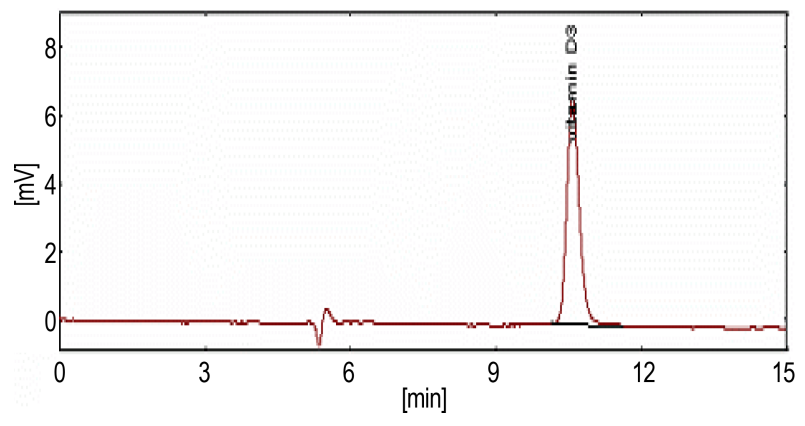

Fig. 1. Chromatogram of vitamin D standard in mobile phase methanol:ethanol: $\mathrm{H}_{2} \mathrm{O}(74.7: 8.3: 17, \mathrm{v} / \mathrm{v})$.

vitamin D peak was sharp and symmetrical, as shown in Fig. 1. Seven different mobile phases except methanol :ethanol: $\mathrm{H}_{2} \mathrm{O}(74.7: 8.3: 17, \mathrm{v} / \mathrm{v})$ did not present adequate responses for vitamin $\mathrm{D}$ quantitation and provided unsuitable retention times for the active substance. This result shows that the eluent comprising only with methanol or acetonitrile plus $\mathrm{H}_{2} \mathrm{O}$ is not sufficient to separate and detect vitamin $\mathrm{D}$ in the test solution. Ethanol showed great efficiency to synergize for separating in the column and detect with UV.

\section{Focusing and analytical step}

At the focusing step, the reverse phase $\mathrm{C}_{18}$ (Capcell-pak UG120V, $2.0 \times 35 \mathrm{~mm}, 5 \mu \mathrm{m}$ ) column was used in focusing column and ethanol:methanol $(10: 90, \mathrm{v} / \mathrm{v})$ was used in mobile phase. At the analytical step, two different mobile phases were tested. A reverse phase $\mathrm{C}_{18}$ (Capcell- pak UG120V, $4.6 \times 250 \mathrm{~mm}, 5 \mu \mathrm{m}$ ) column was tested in methylene chloride:methanol $(10: 90, \mathrm{v} / \mathrm{v})$ and ethanol: methanol $(10: 90, \mathrm{v} / \mathrm{v})$. The reverse phase $\mathrm{C}_{18}$ (Capcellpak UG120V, $4.6 \times 250 \mathrm{~mm}, 5 \mu \mathrm{m})$ column had a high separate efficiency in an ethanol:methanol $(10: 90, \mathrm{v} / \mathrm{v})$ mobile phase. The separated vitamin D peak was sharp and symmetrical, and this condition avoided interferences from equipment noise. The reverse phase $\mathrm{C}_{18}$ column and an ethanol:methanol $(10: 90, \mathrm{v} / \mathrm{v})$ mobile phase were determined to be the optimum conditions for the analytical step (Fig. 2). This result shows that the polarity of ethanol was more efficient to separate vitamin $\mathrm{D}$ in infant formula than methylen chloride.

\section{Method Validation}

The method validation were evaluated according to ICH harmonized tripartite guideline, IUPAC technical report and AOAC guideline (AOAC Committee report, 1989; ICH Expert Working Group, 2005; Michael et al., 2002). The linearity of this method was calculated with a value of the coefficient of determination $\left(r^{2}\right) \geq 0.9999$. The LOD is defined as the lowest active substance concentration that can be determined by the method. By contrast, the LOQ is the concentration of the sample that is obtained with adequate precision and accuracy. An estimation of the limits can be achieved by determination of the signal/ noise ratios at 3:1 (LOD) and 10:1 (LOQ). For the new HPLC method for vitamin D determination, the LOD and LOQ values were 1.51 and $4.95 \mu \mathrm{g} / \mathrm{kg}$, respectively (Table

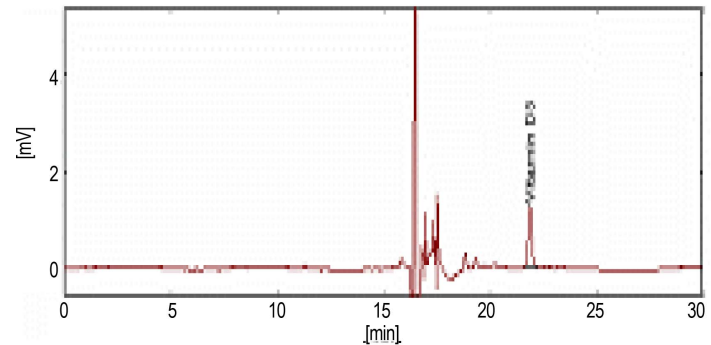

(a) vitamin D standard

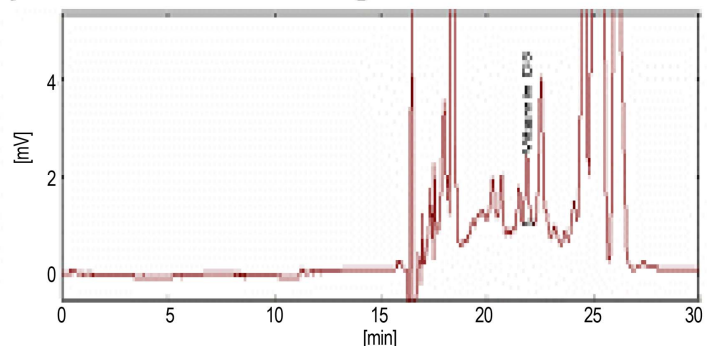

(b) vitamin D in SRM

(in methylene chloride:methanol (10:90, v/v))

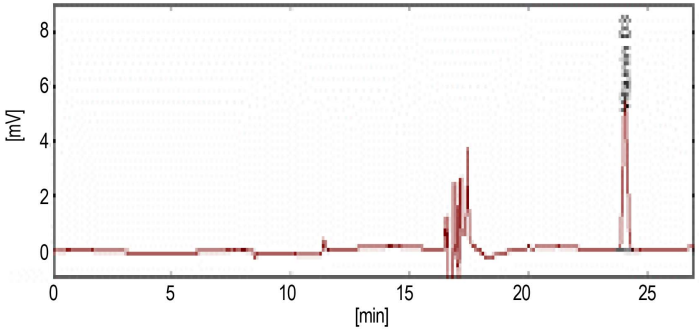

(c) vitamin D standard

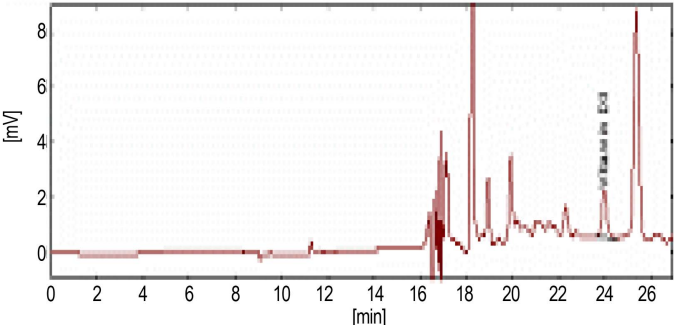

(d) vitamin D in SRM

(in EtOH:MeOH $(10: 90, \mathrm{v} / \mathrm{v})$ )

Fig. 2.Chromatograms of vitamin D standard and SRM in various mobile phases. 
Table 1. Analysis instrument conditions of vitamin D by column-switching HPLC systmems

\begin{tabular}{cl}
\hline \hline Parameter & \multicolumn{1}{c}{ Condition } \\
\hline \multirow{2}{*}{ Column } & $\begin{array}{l}\text { Pre-separation column: Capcell-pak MF } \mathrm{C}_{8}(4.6 \times 150 \mathrm{~mm}, 5 \mu \mathrm{m}) \\
\text { Focusing column: Capcell-pak UG120V } \mathrm{C}_{18}(2.0 \times 35 \mathrm{~mm}, 5 \mu \mathrm{m}) \\
\text { Analytical column: Capcell-pak UG } 120 \mathrm{~V} \mathrm{C}_{18}(4.6 \times 250 \mathrm{~mm}, 5 \mu \mathrm{m})\end{array}$ \\
\hline \multirow{2}{*}{ Flow rate } & $\begin{array}{l}\text { Pre-separation column: } 300 \mu \mathrm{L} / \mathrm{min} \\
\text { Focusing/Analytical column: } 500 \mu \mathrm{L} / \mathrm{min}\end{array}$ \\
\hline \multirow{2}{*}{ Oven temperature } & Focusing column: room temperature \\
& Pre-separation/Analytical column: $40^{\circ} \mathrm{C}$ \\
\hline \multirow{2}{*}{ Mobile phase } & Pre-separation column: methanol:ethanol: $\mathrm{H}_{2} \mathrm{O}(74.7: 8.3: 17, \mathrm{v} / \mathrm{v})$ \\
\hline Injection volume & Focusing/Analytical column: methanol:ethanol $(90: 10, \mathrm{v} / \mathrm{v})$ \\
\hline Detection & $210 \mu \mathrm{L}$ \\
\hline Dissolving solution & $\mathrm{UV} 254 \mathrm{~nm}$ \\
\hline Sampling volume & Methanol $5 \mathrm{~mL}$ \\
\hline
\end{tabular}

3). As shown in Table 2, the new HPLC method provided adequate accuracy $(99.00 \pm 1.53-102.01 \pm 3.04 \%)$ for vitamin D quantitation from infant formula. To calculate the precision, intra- and inter-day tests were performed and the results are expressed as the relative standard deviation (R.S.D., \%) in terms of the area ratio of vitamin D. The low R.S.D. values (1.68 $\pm 0.03-5.75 \pm 0.33 \%)$ revealed the appropriate precision of this new method. The experiments were performed using infant formula SRM 1846 for the recovery test. Infant formula SRM 1846 contains $117.00 \pm 11.00 \mu \mathrm{g} / \mathrm{kg}$ of vitamin D. Three replicates of each SRM 1846 sample were used. Within each analytical series, three calibration standards covering the expected concentration range and three SRM 1846 samples were processed. The recovery rate was calculated by determining the percentage difference between the theoretical concentrations of vitamin D in SRM 1846 and those obtained by chromatographic analysis. As shown in Table 4, an adequate recovery rate for vitamin $\mathrm{D}$ was obtained with the new HPLC method and KFDA official method (KFDA,

Table 2. Accuracy and precision of vitamin $D$ determination

\begin{tabular}{cccccc}
\hline \hline \multirow{2}{*}{$\begin{array}{c}\text { Content } \\
(\mu \mathrm{g} / \mathrm{kg})\end{array}$} & \multicolumn{2}{c}{ Intraday $(\mathrm{n}=3)$} & & \multicolumn{2}{c}{ Interday $(\mathrm{n}=3)$} \\
\cline { 2 - 3 } \cline { 5 - 6 } & $\begin{array}{c}\text { Precision } \\
\mathrm{CV}, \%)\end{array}$ & $\begin{array}{c}\text { Accuracy } \\
(\%)\end{array}$ & & $\begin{array}{c}\text { Precision } \\
(\mathrm{CV}, \%)\end{array}$ & $\begin{array}{c}\text { Accuracy } \\
(\%)\end{array}$ \\
\hline 10 & $1.68 \pm 0.03$ & $101.00 \pm 2.31$ & & $1.73 \pm 0.03$ & $99.00 \pm 1.53$ \\
40 & $3.13 \pm 0.10$ & $100.03 \pm 2.77$ & & $2.80 \pm 0.08$ & $102.01 \pm 3.04$ \\
80 & $5.75 \pm 0.33$ & $102.01 \pm 0.59$ & & $2.96 \pm 0.09$ & $101.02 \pm 0.50$ \\
\hline
\end{tabular}

Table 3. Detective and quantitative limits of vitamin D

\begin{tabular}{ccc}
\hline \hline \multirow{2}{*}{ Element } & \multicolumn{2}{c}{ Switching system method } \\
\cline { 2 - 3 } & LOD $(\mu \mathrm{g} / \mathrm{kg})$ & LOQ $(\mu \mathrm{g} / \mathrm{kg})$ \\
\hline Vitamin D & 1.51 & 4.95 \\
\hline
\end{tabular}

2009). The results were obtained by two methods were $85.20 \pm 3.00$ and $84.09 \pm 2.58 \%$, respectively. The values have no significant difference $(p>0.05)$ at the $95 \%$ of confidence level by the Student's $t$-test. To evaluate the inter-laboratory tests of this method, a recovery test was performed by three laboratories. Infant formula SRM 1846 containing $117.00 \pm 11.00 \mu \mathrm{g} / \mathrm{kg}$ of vitamin D was used as the Certified Reference Material (CRM). Table 5 shows the results of the validation of the inter-laboratory test using this method. The recovery rates were in the range of $85.20 \pm 3.00 \%-89.13 \pm 2.17 \%$ and the result shows that the method is satisfied for inspection of vitamin D in infant formula.

\section{Vitamin D analysis in infant formula}

The results of the analysis of 16 kinds of commercial infant formula are shown in Table 6. The pre-separated samples were analyzed by HPLC with a switching valve.

Table 4. Recovery rate of vitamin $D$ by two methods

\begin{tabular}{lccc}
\hline \hline Analysis method & $\begin{array}{c}\text { Content } \\
(\mu \mathrm{g} / \mathrm{kg})\end{array}$ & $\begin{array}{c}\text { Recovery } \\
(\%)\end{array}$ & $\begin{array}{c}\text { Standard } \\
\text { content } \\
(\mu \mathrm{g} / \mathrm{kg})\end{array}$ \\
\hline New method & $99.69 \pm 3.51$ & $85.20 \pm 3.00$ & $117.00 \pm 11.00$ \\
KFDA method (2009) & $98.38 \pm 3.02$ & $84.09 \pm 2.58$ & \\
\hline
\end{tabular}

Table 5. Inter-laboratory recoveries of vitamin D determination from three laboratories by column-switching HPLC with the UV detection method

\begin{tabular}{cccc}
\hline \hline Laboratory & $\begin{array}{c}\text { Content } \\
(\mu \mathrm{g} / \mathrm{kg})\end{array}$ & $\begin{array}{c}\text { Reference content } \\
(\mu \mathrm{g} / \mathrm{kg})\end{array}$ & $\begin{array}{c}\text { Recovery } \\
(\%)\end{array}$ \\
\hline $\mathrm{A}$ & $99.69 \pm 3.51$ & $117.00 \pm 11.00$ & $85.20 \pm 3.00$ \\
$\mathrm{~B}$ & $104.28 \pm 2.54$ & $117.00 \pm 11.00$ & $89.13 \pm 2.17$ \\
$\mathrm{C}$ & $103.35 \pm 2.41$ & $117.00 \pm 11.00$ & $88.33 \pm 2.06$ \\
\hline
\end{tabular}


Table 6. Determination of vitamin $D$ content in 16 kinds of commercial infant formula

\begin{tabular}{cccr}
\hline \hline Sample No. & $\begin{array}{c}\text { Content } \\
(\mu \mathrm{g} / \mathrm{kg})\end{array}$ & Sample No. & \multicolumn{1}{c}{$\begin{array}{c}\text { Content } \\
(\mu \mathrm{g} / \mathrm{kg})\end{array}$} \\
\hline 1 & $100.10 \pm 0.08$ & 9 & $107.10 \pm 0.02$ \\
2 & $102.00 \pm 0.25$ & 10 & $105.10 \pm 0.04$ \\
3 & $100.10 \pm 0.01$ & 11 & $91.10 \pm 0.06$ \\
4 & $99.00 \pm 0.18$ & 12 & $95.10 \pm 0.47$ \\
5 & $106.10 \pm 0.52$ & 13 & $95.10 \pm 0.53$ \\
6 & $105.00 \pm 0.14$ & 14 & $101.10 \pm 0.03$ \\
7 & $105.10 \pm 0.01$ & 15 & $108.10 \pm 0.32$ \\
8 & $99.00 \pm 0.06$ & 16 & $103.10 \pm 0.28$ \\
\hline
\end{tabular}

The new HPLC vitamin D method was applied to vitamin $\mathrm{D}$ analysis. The vitamin D content was determined by comparing the concentrations of the standard vitamin D and those obtained by chromatographic analysis. By comparison to the concentration on the label of the commercial infant formula, the vitamin D was adequately analyzed by new chromotographic analysis. Also, all of the results were in the range of CODEX standard (Codex, 2007).

\section{Discussion}

The newly developed method provides for good resolution in the determination of vitamin $\mathrm{D}$ with a columnswitching HPLC system and UV-Vis detection. The improved pre-separation and instrument analysis gave acceptable and reproducible recoveries. The new HPLC method for vitamin D determination described in the present study was validated by linearity, sufficient accuracy, recovery, precision, and low values of limits of detection and quantification, thereby confirming the sensitivity of this analytical tool. This new HPLC method for vitamin $\mathrm{D}$ determination allows for a low-cost mobile phase and high specificity. In addition to these advantages, the new analytical method allowed for automation of the pre-separation and focusing procedures by the HPLC system. Therefore, this new analytical method should provide a time-saving advantage in comparison to other previously used methods and is particularly attractive for the determination of vitamin $\mathrm{D}$ in infant formula.

\section{Acknowledgements}

The work performed in this study was supported the by Korea Food and Drug Administration research project (KFDA 09081KFDA088) in 2009. We would like to thank Dr. Jayoung Jeong, Dr. Leem Dong-gil and Mr. Taehyung Yoon of KFDA nutrition and functional food research team. We also thank Prof. Kyong-Su Kim of Chosun university, for helping as project partner.

\section{References}

1. AOAC Committee report (1989) Guidelines for collaborative study of procedure to validate characteristics of a method of analysis. J. Assoc. Off. Anal. Chem. 72, 694-704.

2. AOAC (2005) Official Methods of Analysis. 18th ed, Association of Official Analytical Chemists, Gaithersburg, Maryland, USA. 50, pp. 5-6.

3. Bell, N. H., Stern, P. H., Panther, E., Sinha, T. K. and DeLuca, H. F. (1979) Evidence that increased circulating 1 $\alpha, 25$-dihydroxyvitamin $\mathrm{D}$ is the probable cause for abnormal calcium metabolism in sarcoidosis. J. Clin. Invest. 64, 218.

4. Brunetto, M. R., Obando, M. A., Gallignani, M., Alarcon, O. M., Nieto, E., Salinas, R., J. Burguera, L., and Burguera, M. (2004) HPLC determination of Vitamin D3 and its metabolite in human plasma with on-line sample cleanup. Talanta 64, 1364-1370.

5. Christians, U. and Jacobsen, W., and Serkova, N. (2000) Automated, fast and sensitive quantification of drugs in blood by liquid chromatography-mass spectrometry with on-line extraction: immunosuppressants. J. Chromatogr. B 748, 41-53.

6. Codex (2007) Standard for infant formula and formulas for special medical purposes intended for infants. Codex Stan. 721981.

7. Donald, W. S. and Gerhard, G. (1992) The kidney: Physiology and physiopathology. 2nd ed, Raven Press, New York.

8. Friedrich F. (1988) Vitamin D. In: Vitamins. Walter De Gruyter, Berlin, p. 143.

9. Gharbo, S. A. and Gosser, L. A. (1974) A stable and sensitive colorimetric method for the determination of ergocalciferol (vitamin D2) by using trifluoroacetic acid. Analyst. 99, 222224.

10. Hartmann, S., Froescheis, O., Ringenbach, F., Wyss, R., Bucheli, F., Bischof, S., Bausch, J., and Wiegand, U. W. (2001) Determination of retinol and retinyl esters in human plasma by high-performance liquid chromatography with automated column switching and ultraviolet detection. J. Chromatogr. B 751, 265-275.

11. Hassan, S. S. (1980) Colorimetric determination of vitamin D2 (calciferol). Methods Enzymol. 67, 323-326.

12. Heudi, O., Trisconi, M. J., and Blake, C. J. (2004) Simultaneous quantification of Vitamins A, D3 and E in fortified infant formulae by liquid chromatography-mass spectrometry. J. Chromatogr. A 1022, 115-123.

13. ICH Expert Working Group (2005) Validation of analytical procedures: text and methodology Q2(R1). ICH Harmonised tripartite guideline Step 4, 1-18.

14. Kamao, M., Tsugawa, N., and Suhara, Y. (2007) Quantification of fat-soluble vitamins in human breast milk by liquid chromatography-tandem mass spectrometry. J. Chromatogr. B 859, 192-200.

15. KFDA (Korea Food and Drug Administration) (2009) Food 
Standards Codes. Korean Foods Industry Association, Seoul, Korea. pp. 745-747.

16. Knebel, N.G., Grieb. S., and Leisenheimer, S. (2000) Determination of retigabine and its acetyl metabolite in biological matrices by on-line solid-phase extraction (column switching) liquid chromatography with tandem mass spectrometry. $J$. Chromatogr. B 748, 97-111.

17. Michael, T., Stephen. R. E., and ROGER, W. (2002) Harmonized guidelines for singlelaboratory validation of methods of analysis (IUPAC technical report). Pure Appl. Chem. 74, 835855.

18. Soldin, O. P., Sharma, H., and Husted, L. (2009) Pediatric reference intervals for aldosterone, $17 \alpha$-hydroxyprogesterone, dehydroepiandrosterone, testosterone and 25-hydroxy vitamin D3 using tandem mass spectrometry. Clin. Biochem. 42, 823827.

19. The commission of the European communities. (2006) Commission directive 2006/141/EC of 22 December 2006 on infant formulae and follow-on formulae and amending directive 1999/21/EC. Official Journal of the European Union. Available from: http://eur-lex.europa.eu/LexUriServ/site/en/ oj/2006/1_401/1_40120061230en00010033.pdf. Accessed Feb. 27,2012 .

(Received 2012.3.5/Revised 1st 2012.4.24, 2nd 2012.8.7/ Accepted 2012.9.4) 